\title{
Knowledge management in multi-generation workforce: investigation on critical success factor and strategy
}

\author{
I Komang Artha Winadi ${ }^{1,}$, Amalia Suzianti ${ }^{2}$, and Romadhani Ardi $^{3}$ \\ ${ }^{1}$ Industrial Engineering, Universitas Indonesia, Depok, Indonesia
}

\begin{abstract}
This paper investigates critical success factors and strategy of knowledge management within organization that made of multi generation workforce. It is widely understood that tensions and conflicts are inevitable if employees from every generational cohort fail to understand and accept the unique characteristics of each group. As the race to gain competitive advantage between businesses growing intensely from time to time, there is a need emerging for a strong guidance in developing a correct knowledge management strategy in respect to multi-generation work force phenomenon. By incorporating knowledge management critical success factor and strategy and also generational differences obtained from literature review, we design models that can be used to choose appropriate knowledge management strategy in a multi generational workforce organization. Using these models, which were validated using Structural Equation Modelling (SEM), it is found that the appropriate knowledge management strategy for multi generation work force organization is external personalization.
\end{abstract}

\section{Introduction}

The rate of technology development has increased rapidly during the last decade that directly affect customer behavior. The advancement of technology creates new opportunity and subsequently new competition. To keep up with this challenge, organization should possess and continuously increase their competitive advantage, where innovation is a key factor [1]. It is widely accepted that one of the common approach to support innovation in an organization is knowledge management.

Knowledge management can be defined as the process of creating, sharing, using and managing the knowledge and information of an organization [2]. Knowledge management has been regarded as a major part of organizational success due to the increasing recognition towards knowledge as a valuable asset within the organization [3] ; [4].

${ }^{1}$ Corresponding author: komangwinadi89@gmail.com 
Copious academic research has been conducted in the area of knowledge management, especially in terms of knowledge management implementation. Eventhough it is safe to say that there is a sufficient theoretical foundation available for practitioners to implement knowledge management strategy, there are circumstances that force organization to continuously improve their innovative power [5], such as a disruptive business environment; customer loyalty and switching provider behavior; and also first-mover advantages. These condition entitled organization to enhance their knowledge management strategy in order to gain the competitive advantage.

Judging from current researches, the aspect that is rather overlooked is the phenomenon of multi-generation work force within an organization. Multiple generations had worked in the same organization for quite a while, however they were usually separated by job descriptions and system hierarchy [6]. Right now it is very common to see younger people supervising older employee with their own generational differences. These differences could potentially ignite work tensions and conflicts if employees from each generation fail to compromise [7].

Although this condition is already being observed by several knowledge management researcher, such as [4] ; [8] ; [9], they mainly emphasize on the differences that follows generational cohorts and does not provide any insight on what kind of strategy that should be used to cope with that differences. As the race to gain competitive advantage growing intensely from time to time, there is a need emerging for a strong guidance in developing a correct knowledge management strategy in respect to multi-generation work force phenomenon [10]. Therefore the objective of this paper is to propose a model that can be used to choose knowledge management strategy in a multi generational workforce organization.

\section{Literature Review}

There are several factors that proved to be critical towards the success of knowledge management implementation or also known as the critical success factors of knowledge management. There are numerous researches that proposed their own respective ideas about these factors such as [11], [12] and also [13]. In terms of generalization on these factors, [14] managed to find a common ground and define a classification of knowledge management critical success factor, which consist of Culture, Structure and Procedures, Human and Financial Resources, Technology and Infrastructures, Strategy and Leadership and KM Processes.

By using Theory of Planned Behavior (TPB) perspective, [15] introduce a conceptual model that predict knowledge management success through two variables namely Performance Ability and Performance Willingness. Performance ability defined as the organization capability to implement knowledge management that is taken from TPB's perceived behavioral control and Performance Willingness is defined as the organization willingness or motivation to implement knowledge management which is taken from TPB's intention factor.

Knowledge management strategy can be defined as the basic reference that can be used in order to manage knowledge within an organization [16]. According to [17], knowledge management strategy is classified into two kinds, which are codification and personalization. Based on this information, [18] elaborate these two strategies into four strategies that incorporate type and origin of knowledge, which are Internal Personalization, Internal Codification, External Personalization and External Codification. It is suggested by [18] that organization should choose the strategy that is best suited with their IS Maturity and Knowledge Intensity. IS maturity is defined as organization's IS capability to utilize internal and external information to support knowledge management process while 
knowledge intensity is defined as organization's intensity to find and exploit internal and external knowledge.

In the history of workforce, it can be said that it is the first time where employees from various generations not only working side by side but also directly both with people who are as young as their children and as old as their parents [19]. These differences should be handled carefully in order to prevent potential conflict and tension between employees from each generation [7]. To get a better understanding of each generation, the summary of notable characteristic for each generation obtained from literature review will be shown in Table 2 .

Table 1.Generational differences (Summarized from [6]; [7]; [20]; [21])

\begin{tabular}{|c|c|c|}
\hline Aspect & Gen $X$ & Gen Y \\
\hline \multirow{2}{*}{ Philosopy } & $\begin{array}{l}\text { Favors order dan } \\
\text { responsibility }\end{array}$ & Favors risk taking and freedom \\
\hline & Work to live & Live first, then work \\
\hline Top Developmental Areas & $\begin{array}{l}\text { - Leadership } \\
\text { - Skill training in my areas } \\
\text { of expertise } \\
\text { - Team Building }\end{array}$ & $\begin{array}{l}\text { - Leadership } \\
\text { - Problem solving, decision } \\
\text { making } \\
\text { - Skill training in my areas of } \\
\text { expertise }\end{array}$ \\
\hline Prefered Leadership Attributes & $\begin{array}{l}\text { - Credible } \\
\text { - Trusted } \\
\text { - Farsighted }\end{array}$ & $\begin{array}{l}\text { - Listen wells } \\
\text { - Dependable } \\
\text { - Dedicated }\end{array}$ \\
\hline \multirow{2}{*}{ Individual Characteristic } & Individualist & The more the merrier \\
\hline & Technology savvy & Technology savvy \\
\hline
\end{tabular}

\section{Methodology}

By incorporating knowledge management critical success factor and generational differences, we design models that enable their user to choose an appropriate knowledge management strategy based on their organization characteristic. In order to validate the model, a data collection process is conducted.

A questionnaire is then designed based on the literature review and modification from the field study. The instrument items are measured on a five point (1-5) Likert scales, of which 1 indicates that the respondent strongly disagree with the statement and 5 indicates that the respondent strongly agree with the statement respectively. The questionnaire is pretested by three knowledge workers, pilot tested among 30 employees to ensure content validity. This study undertakes the main survey to 253 subjects among the organization that consist of multi generation workforce and located in Indonesia. Using the data collected by questionnaire, a Confirmatory Factor Analysis (CFA) is performed to specify the structure between observed indicators and latent constructs, and test the validity of measurement model. Subsequently, structural equations among latent constructs are examined to test the conceptual structural equation model (SEM). The CFA and SEM procedures are conducted using AMOS software. The result of calculation using SEM subsequently deployed into the model to choose the appropriate knowledge management strategy 


\section{Model and hypothesis development}

\subsection{Knowledge Management Implementation Model}

By incorporating insight from two previous researches on knowledge management critical success factor [14]; [15], we managed to generate a model that enable organization to assess their workforce characteristic. The classification of critical success factor into KM Ability (KMA) and KM Willingness (KMW) construct is supported by the previous research conducted by [15] and [22]. The model is shown in Figure 1.

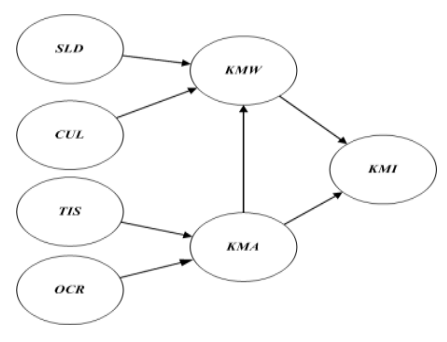

Fig.1. KM Implementation (KMI) Model

The description of each variable included in the model is as follows:

- OCR stands for Organizational Characteristic; this variable represents the activities and procedures that support knowledge management implementation and also the policies on people management that is the heart of organizational knowledge.

- TIS stand for Technology and Infrastructure, this variable represents the organization capability on information technologies and communication systems.

- CUL stands for Culture; this variable represents values and beliefs that are invented, shared and developed by group of people in the organization.

- $\quad$ SLD stands for Strategy and Leadership, this variable represents strategic planning and leadership issue in terms of knowledge management implementation.

- KMA stands for KM Ability; this variable represents organization capability to implement knowledge management.

- KMW stands for KM Willingness; this variable represents organization willingness or motivation to implement knowledge management.

- KMI stands for KM Implementation; this variable represents the magnitude of knowledge management implementation towards organizations business process.

\subsection{Knowledge Management Strategy Model}

Adopting the model from [18], we propose a slight adjustment which is to replace IS Maturity with KM Ability and Knowledge Intensity with KM Willingness. This adjustment is made due to the comparable definitions between them. By adjusting this model, the result of the quantitative analysis using SEM from KM Implementation model can be used to choose the right knowledge management strategy. The parameter that we proposed to be used in determining strategy position is the Standardized Regression Weight of KMA $\rightarrow$ $\mathrm{KMI}$ and KMW $\rightarrow \mathrm{KMI}$ with the center point of the quadrant should be 0.5 , which means a beta $(\beta)$ score less than 0.5 will be considered as low and vice versa. The calculation using these models should be conducted for the entire organization and also for each generation in order to identify the right strategy for the whole organization and each cohort. 


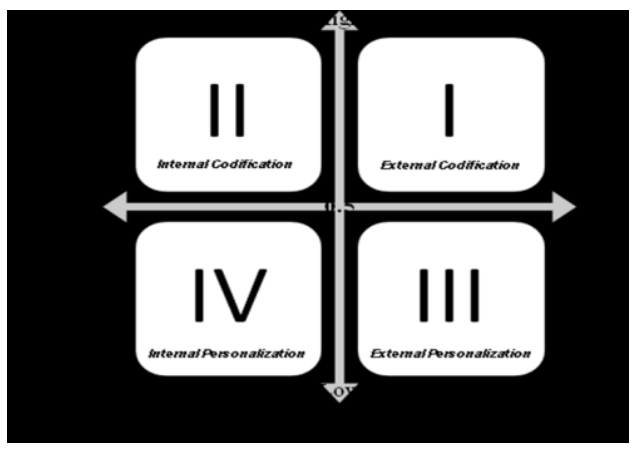

Fig.2. KM Strategy (KMS) Model

Table 2.Research hypotheses

\begin{tabular}{|c|c|c|c|}
\hline \multicolumn{1}{|c|}{ Hypothesis } & \multicolumn{3}{|c|}{ Code } \\
\hline OCR has a positive and significant relation towards KMA & H1a & H1b & H1c \\
\hline TIS has a positive and significant relation towards KMA & H2a & H2b & H2c \\
\hline CUL has a positive and significant relation towards KMA & H3a & H3b & H3c \\
\hline SLD has a positive and significant relation towards KMA & H4a & H4b & H4c \\
\hline KMA has a positive and significant relation towards KMW & H5a & H5b & H5c \\
\hline KMA has a positive and significant relation towards KMI & H6a & H6b & H6c \\
\hline KMW has a positive and significant relation towards KMI & H7a & H7b & H7c \\
\hline There is a significant differences of OCR between Gen X and Gen Y & \multicolumn{3}{|c|}{ H8 } \\
\hline There is a significant differences of TIS between Gen X and Gen Y & \multicolumn{3}{|c|}{ H10 } \\
\hline There is a significant differences of CUL between Gen X and Gen Y & \multicolumn{3}{|c|}{ H11 } \\
\hline There is a significant differences of SLD between Gen X and Gen Y & \multicolumn{3}{|c}{ H12 } \\
\hline Gen X would prefer Internal Codification Strategy & \multicolumn{3}{|c}{ H14 } \\
\hline Gen Y would prefer External Codification Strategy & \multicolumn{3}{|c}{} \\
\hline Multi Generation Work Force Organization would prefer External & & \\
\hline Codification Strategy & & \\
\hline
\end{tabular}

Note: (a) Gen X; (b) Gen Y; (c) Multi Generation Work Force Organization

\section{Data analysis and result}

The number of respondent involved in the survey are 283 , of which consist of $35 \%$ Gen $X$ (100 respondent) and $65 \%$ Gen Y (183 respondent). Subject that has more than 10 years of work experience are $44 \%$, while $41 \%$ and $15 \%$ have worked $2-5$ years and 5-10 years, respectively. More than half of the subject has the role of staff $(70.7 \%)$, while $20.8 \%$ has the role of supervisor, and the rest of them $(8.5 \%)$ has the role of manager or higher.

This study first undertakes the CFA to confirm the validity of the constructs and to assess the model fit. Convergent validity of CFA results that consist of construct reliability and average variance extracted are shown by table 3 . The model adequacy was assessed by the fit indices suggested by [23]; [24] and shown by table 4 . The results indicate that the measurement model has good convergent validity. Therefore, the proposed measurement model is reliable and meaningful to test the structural relationships among the constructs. 
Table 3.Convergent Validity

\begin{tabular}{|c|c|c|c|c|c|c|c|}
\hline Item & OCR & TIS & CUL & SLD & KMA & KMW & KMI \\
\hline CR & 0.92 & 0.94 & 0.84 & 0.89 & 0.90 & 0.87 & 0.93 \\
\hline AVE & 0.55 & 0.70 & 0.57 & 0.62 & 0.74 & 0.69 & 0.76 \\
\hline
\end{tabular}

Table 4.Fit Indices for Measurement and Structural Model

\begin{tabular}{|c|c|c|c|c|}
\hline Indices & \multicolumn{2}{|c|}{$\begin{array}{c}\text { Standard and } \\
\text { Reference }\end{array}$} & $\begin{array}{c}\text { Measurement } \\
\text { Model }\end{array}$ & $\begin{array}{c}\text { Structural } \\
\text { Model }\end{array}$ \\
\hline $\mathrm{X}^{2} / \mathrm{df}$ & $<3.00$ & {$[23]$} & 2.109 & 2.125 \\
\hline $\mathrm{CFI}$ & $>0.90$ & {$[24]$} & 0.933 & 0.901 \\
\hline SRMR & $<0.08$ & {$[24]$} & 0.036 & 0.051 \\
\hline RMSEA & $<0.07$ & {$[24]$} & 0.063 & 0.045 \\
\hline
\end{tabular}

Table 5.Path Analysis Result

\begin{tabular}{|c|c|c|c|c|c|c|}
\hline \multirow{2}{*}{ Path } & \multicolumn{3}{|c|}{ Standardized Regression Weight } & \multicolumn{3}{|c|}{$\begin{array}{c}\text { Critical Ratio (bold is significant in } \mathrm{p} \\
\qquad \mathbf{0 . 1 0})\end{array}$} \\
\hline & $\mathbf{A}$ & B & $\mathbf{C}$ & $\mathbf{A}$ & B & $\mathbf{C}$ \\
\hline $\mathrm{OCR} \rightarrow \mathrm{KMA}$ & 0.465 & 0.362 & 0.407 & 1.84 & 2.74 & 3.53 \\
\hline TIS $\rightarrow$ KMA & 0.446 & 0.579 & 0.529 & 1.76 & 4.26 & 4.51 \\
\hline $\mathrm{CUL} \rightarrow \mathrm{KMW}$ & -0.350 & 0.374 & 0.180 & -1.18 & 2.89 & 1.91 \\
\hline $\mathrm{SLD} \rightarrow \mathrm{KMW}$ & 0.865 & 0.353 & 0.519 & 2.60 & 1.72 & 3.51 \\
\hline $\mathrm{KMA} \rightarrow \mathrm{KMW}$ & 0.453 & 0.290 & 0.296 & 3.11 & 2.02 & 2.83 \\
\hline $\mathrm{KMA} \rightarrow \mathrm{KMI}$ & 0.293 & 0.150 & 0.272 & 1.61 & 0.99 & 2.34 \\
\hline $\mathrm{KMW} \rightarrow \mathrm{KMI}$ & 0.703 & 0.780 & 0.679 & 3.78 & 4.97 & 5.73 \\
\hline
\end{tabular}

Note: (A) Gen X; (B) Gen Y; (C) Multi Generation Work Force Organization

Table 6.Comparison between Generations

\begin{tabular}{|c|c|c|c|c|}
\hline Variable & Gen X & Gen Y & Comparison z-Score & Conclusion \\
\hline OCR & 0.465 & 0.362 & -0.218 & No significant differences \\
\hline TIS & 0.446 & 0.579 & 0.595 & No significant differences \\
\hline CUL & -0.35 & 0.374 & 2.252 & There is a significant differences \\
\hline SLD & 0.865 & 0.353 & -1.395 & No significant differences \\
\hline
\end{tabular}

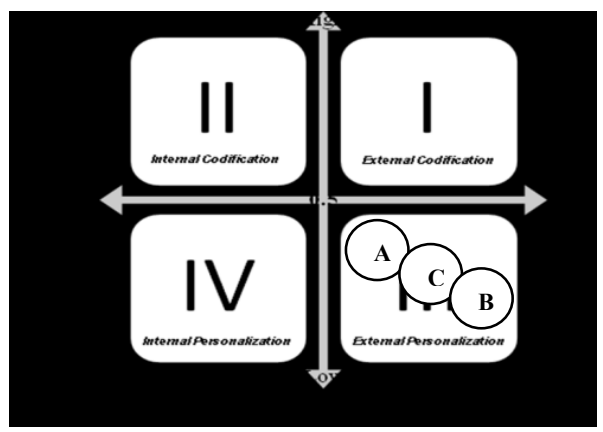

Fig.3. KM Strategy Deployment for Gen X (A), Gen Y (B) and Multi Generation Work Force Organization $(\mathrm{C})$ 


\section{Discussion}

\subsection{Knowledge Management Implementation Model}

Based on the SEM calculation, it is found that for Generation X, OCR and TIS has a positive and significant effect on KMA, while SLD has a positive and significant effect on KMW. These findings confirm the result of the research conducted by [11]. It is also found that CUL has a negative albeit not significant effect on KMW, where this finding somewhat reflect the individualist characteristic of Generation X [6]; [7]; [20]; [21].

For Generation Y, OCR and TIS has a positive and significant effect on KMA, while CUL and SLD also have a positive and significant effect on KMW. It can be seen that for both Generation X and Y, KMA does not have a significant effect towards KMI but have a significant effect on KMW, thus it can be said that KMA became the catalyst for KMW to enforce KMI. These findings justify other research result that stated there is a significant effect of ability to implement knowledge management towards intention to implement them [22].

Further analysis between the critical success factor of Generation X and Y discover that Culture (CUL) has a significant difference. Since culture is highly supported by collaboration, and collaboration is affected by individualism, this finding emphasizes a different characteristic between Gen $\mathrm{X}$ as the individualist or lone wolf and Generation $\mathrm{Y}$ as their polar opposite which hold the philosophy of the more the merrier [6];[7].

\subsection{Knowledge Management Strategy Model}

Based on the value of standardized regression weight of KMA and KMW towards KMI, it was found that External Personalization Strategy is the suitable knowledge management strategy that should be used for Gen X, Gen Y and also the whole organization. Although this result is different from the hypothesis proposed by this research, it is supported by other research that highlights the importance of motivation and willingness towards knowledge management implementation [25].

\subsection{Potential Contribution towards Industry 4.0}

Alongside a wide array of opportunities that comes with the automation and digitization of Industry 4.0, they also possess some challenges of their own. As stated by [26], one of the emerging challenges in Industry 4.0 is the changes in workplace demographic. The admission of younger generation in the workplace presents a new challenge on the ability to transfer knowledge, mainly because their characteristic differences with the older generation already settled in the workplace. If not treated correctly, this condition could incapacitate organization's capability to retain and at the same time expand their knowledge base.

By incorporating knowledge management critical success factor, strategy and also generational differences, this research manage to design models that could be used in deciding suitable knowledge management strategy for multi generation work force organization. With knowledge management strategy that is suitable with their respective workplace demographic, organization could then overcome the demographic challenges of Industry 4.0 and reap the maximum benefit from the opportunities that they offer. 


\section{Future research}

As with any research, the specific context of this study limits the interpretation of the findings. Some adjustments must be made to apply these results, such as generalization in a broader region such as Asia or in the international setting. Another aspect that is interesting to be examined for future research is the introduction of Generation $\mathrm{Z}$ into the workforce. With their unique characteristic, the inclusion of Gen $\mathrm{Z}$ in the model could possibly generate a different result compared to this research.

Thanks are due to the Directorate of Research and Community Service (DRPM) Universitas Indonesia, which has supported and facilitated this research through PITTA Grant (2374/UN2.R3.1/HKP.05.00/2018).

\section{References}

1. J. M. Trejo, J. S. Gutiérrez and G. M. Guzman, The customer knowledge management and innovation, Contaduría y Administración 61, pp. 456-477 (2016)

2. J. Girard and J. Girard, Defining knowledge management: Toward an applied compendium, Online Journal of Applied Knowledge Management, pp. 1-20 (2015)

3. R. Filippini, W. H. Güttel and A. Nosella, Ambidexterity and the evolution of knowledge management initiatives, Journal of Business Research 65, pp. 317-324 (2012)

4. J. Ž. Brčić and K. K. Mihelič, Knowledge sharing between different generations of employees an example from Slovenia, Economic Research-Ekonomska Istraživanja Vol. 28, pp. 853-867 (2015)

5. R. Nowacki and K. Bachnik, Innovations within knowledge management, Journal of Business Research 69, pp. 1577-1581 (2016)

6. D. Gursoy, T. A. Maier and C. G. Chi, Generational differences An examination of work values and generational gaps in the hospitality workforce, International Journal of Hospitality Management 27, pp. 448-458 (2008)

7. T. Angeline, Managing generational diversity at the workplace: expectations and perceptions of different generations of employee, African Journal of Business Management Vol 5, pp. 249-255 (2011)

8. W. K. McHenry and S. R. Ash, Knowledge Management and Collaboration: Generation X vs. Generation Y, International Journal of Business and Social Science Vol.4, pp. 78-87 (2013)

9. K. Chidambaranathan and S. B.S., Knowledge Management as a Predictor of Organizational Effectiveness:, The Journal of Academic Librarianship 41, pp. 758-763 (2015)

10. V.-H. Lee, A. T.-L. Foo, L.-Y. Leong and K.-B. Ooi, Can competitive advantage be achieved through knowledge management? A case study on SMEs, Expert Systems With Applications 65, pp. 136-151 (2016)

11. L.-S. Huang and C.-P. Lai, An investigation on critical success factors for knowledge management using structural equation modeling, in International Conference on Asia Pacific Business Innovation and Technology (2012)

12. A. Samad, A. K. Kazi and M. Raheem, Critical Success Factors of Knowledge Management Systems Implementation, KASBIT Business Journal (KBJ), pp. 64-78 (2014) 
13. L. A. Y. Al Hakim and S. Hassan, Critical Success Factors of Knowledge Management,Innovation and Organisational Performance: An Empirical Study of the Iraqi Mobile Telecommunication Sector, British Journal of Economics, Finance and Management Sciences Vol. 4, pp. 31-49 (2012)

14. M. Sedighi and F. Zand, Knowledge Management: Review of the Critical Success Factors and Development of a Conceptual Classification Model, in 10th International Conference on ICT and Knowledge Engineering, Bangkok (2012)

15. F. Lehner and N. Haas, Knowledge Management Success Factors - Proposal of an Empirical Research, Electronic Journal of Knowledge Management, pp. 79-90 (2010)

16. L. Mladkova, Knowledge strategy: key player or relict of the past?, in Procedia Social and Behavioral Sciences (2014)

17. M. T. Hansen, N. Nohria and T. Tierney, Whats Your Strategy for Managing Knowledge?, Harvard Business Review (1999)

18. T. H. Kim, J. N. Lee, J. U. Chun and I. Benbasat, Understanding the effect of knowledge management strategies on knowledge management performance: A contingency perspective, Information \& Management, pp. 398-416 (2014)

19. R. Zemke, C. Raines and B. Filipczak, Generations at work: Managing the clash of Veterans, Boomers, Xers and Nexters in your workplace (2nd Ed), New York, NY: American Management Association (2000)

20. A. Tolbize, Generational differences in the workplace (2008)

21. V. Srinivasan, Multi generations in the workforce: Building collaboration, IIMB Management Review, pp. 48-66 (2012)

22. T. Khalil, K. Atieh, A. U. Mohammad and F. Bagdadlian, Examining the Social and Technical Factors Influencing School Teachers Knowledge Sharing Intentions in a Teachers Online Professional Community, The Electronic Journal of Knowledge Management Volume 12 Issue 3, pp. 157-165 (2014)

23. D. Hooper, J. Coughlan and M. R. Mullen, Structural Equation Modelling: Guidelines for Determining Model Fit, Electronic Journal of Business Research Methods Volume 6 Issue 1, pp. 53-60 (2008)

24. J. Hair, Multivariate Data Analysis Fifth Edition, New Jersey: Pearson Higher Education (1998)

25. A. Mathew, G. Nair and L. Rodrigues, Systems Approach to Determine the Significance of the Critical Success Factors of a Knowledge Management System, Research Journal of Management Sciences Vol 1, pp. 28-36 (2012)

26. F. Hecklau, M. Galeitzke, S. Flachs and H. Kohl, Holistic approach for human resource management in Industry 4.0, in 6th CLF - 6th CIRP Conference on Learning Factories (2016) 